\title{
Surgical results of combined pars plana vitrectomy and phacoemulsification for vitreous hemorrhage in PDR
}

This article was published in the following Dove Press journal:

Clinical Ophthalmology

7 August 2013

Number of times this article has been viewed

\author{
Handan Canan' \\ Selçuk Sizmaz ${ }^{2}$ \\ Rana Altan-Yaycioğlu' \\ 'Department of Ophthalmology, \\ Adana Teaching and Medical Research \\ Center, Baskent University School \\ of Medicine, ${ }^{2}$ Department of \\ Ophthalmology, Cukurova University \\ School of Medicine, Yuregir, Adana, \\ Turkey
}

Background: The purpose of this study was to evaluate the effectiveness, safety, and incidence of complications after combined clear corneal phacoemulsification with intraocular lens implantation and pars plana vitrectomy in eyes with proliferative diabetic retinopathy coexistent with significant cataract.

Methods: Eighty-five eyes of 85 patients with proliferative diabetic retinopathy underwent primary standard three-port vitrectomy with 20-gauge instruments and phacoemulsification with intraocular lens implantation for vitreous hemorrhage from 2008 to 2011 . The main outcome measures were visual outcomes and surgical complications.

Results: Forty patients were male and 45 were female. Their age ranged from 40 to 77 years with a mean of 59.6 years. The mean follow-up was 13 months, with a range of 6-48 months. The preoperative $\log \mathrm{MAR}$ visual acuity changed from $2.62 \pm 0.6$ to $0.8 \pm 0.7$ postoperatively. Postoperatively, visual acuity improved in 79 eyes (92.9\%), and did not change in six eyes (7.1\%). Intraoperative complications were transient corneal edema (five eyes) and posterior capsular rupture (one eye). Postoperative complications consisted of transient intraocular pressure elevation (25 eyes), corneal epithelial defects (six eyes), anterior chamber reaction (four eyes), hyphema (two eyes), posterior synechiae (four eyes), vitreous hemorrhage (23 eyes), retinal tears (five eyes), retinal detachment (one eye), and neovascular glaucoma (one eye).

Conclusion: Our study suggests that the combined operation of pars plana vitrectomy, phacoemulsification, and intraocular lens implantation is safe and effective for patients with proliferative diabetic retinopathy. We believe that the visual outcome and complications depended primarily on underlying posterior segment pathology and were not related to the combined procedure technique.

Keywords: cataract, diabetic retinopathy, phacoemulsification, vitrectomy

\section{Introduction}

Vitreoretinal diseases and cataracts frequently occur at the same time in patients with proliferative diabetic retinopathy (PDR), so management of these cases could become problematic. The presence of cataract alters visualization of the fundus during vitreoretinal surgery. On the other hand, it was reported that $75 \%$ of patients left phakic at the end of vitreoretinal surgery develop cataract during follow-up. Moreover, cataract surgery in vitrectomized eyes is usually troublesome, as these eyes lack vitreous support and cannot maintain anterior chamber stability. ${ }^{1-6}$

Combined phacoemulsification and pars plana vitrectomy (PPV) was first introduced in $1998 .^{7}$ because of developments in surgical systems, we are able to achieve a promising outcome. Hence, currently, combined phacoemulsification and pars
Correspondence: Handan Canan Baskent University, Faculty of Medicine, Adana Teaching and Medical Research Center, Dadaloglu M 39 sk No 6, 01250 Yuregir, Adana, Turkey Tel +90 3223272727 ext 2104 Fax +90 322327 I 274

Email handanakkaya@yahoo.com 
plana vitrectomy is gaining popularity in the management of vitreoretinal disorders associated with cataract. ${ }^{8-10}$ The aim of this study was to analyze the results of combined phacoemulsification and PPV in eyes with proliferative diabetic retinopathy and coexisting cataract.

\section{Patients and methods}

The medical records of patients with vitreous hemorrhage due to proliferative diabetic retinopathy (PDR) and coexisting cataract who underwent PPV in combination with phacoemulsification between January 2008 and September 2011 were retrospectively reviewed. Institutional review board approval was obtained. All surgeries were performed by the same surgeon (HC). Patients were informed about the possible complications and a signed written consent form was obtained prior to surgery from all patients. Patients with a follow-up of less than 6 months were excluded.

The charts of the patients were evaluated retrospectively. Preoperative and postoperative visual acuity, slit-lamp biomicroscopy, intraocular pressure (IOP) measurements, and indirect ophthalmoscopy findings were noted. When the fundus could not be visualized, ultrasonography was performed to evaluate the vitreous and the retina. Visual acuity was assessed using the Snellen visual acuity chart and was converted to the logarithm of the minimum angle of resolution ( $\log$ MAR) value for statistical analysis.

The primary outcome measure was the final visual acuity, intraoperative as well as postoperative complications, and anatomic success. Best corrected visual acuity (BCVA) at the postoperative month 6 visit was accepted as the final visual acuity. Anatomic success was defined as a completely attached retina at all visits. Increase in BCVA was accepted as functional success. Intraoperative complications were recorded as corneal edema, posterior capsule tear, and anterior chamber hemorrhage. Postoperative complications included transient IOP rise, anterior chamber reaction, formation of posterior synechia, dislocation of the intraocular lens (IOL), and endophthalmitis.

Surgeries were performed under general anesthesia, and phacoemulsification was performed prior to PPV. Phacoemulsification was performed via a $2.8 \mathrm{~mm}$ clear corneal tunnel with a standard phaco-chop technique. A foldable hydrophilic acrylic IOL was implanted in the bag in the event that the posterior capsule was intact. In cases with posterior capsule defects, a polymethylmethacrylate IOL with an overall diameter of $13 \mathrm{~mm}$ was placed in the ciliary sulcus. The incision was sutured with 10-0 nylon. Vitrectomy was performed using a standard three-port 20-gauge PPV technique.
Sclerotomies were placed $3.5 \mathrm{~mm}$ posterior to the limbus at inferior temporal, superior temporal, and superior nasal quadrants. Vitreoretinal procedures included peeling of the posterior hyaloid membrane, endophotocoagulation, fluid-air exchange, and gas or silicone oil injection in appropriate cases. Finally, due to the severity of proliferative vitreoretinopathy, either medical grade silicone oil of 1000 centistokes viscosity, intraocular perfluoropropane $\left(\mathrm{C}_{3} \mathrm{~F}_{8}\right)$ gas, or sulfur hexafluoride $\left(\mathrm{SF}_{6}\right)$ gas was used as endotamponade, with fluid-air exchange preferred in uncomplicated cases. At the end of the surgery, triamcinolone acetonide $1 \mathrm{mg}$ was injected through a paracentesis into the anterior chamber using a 27-gauge cannula in all cases.

Statistical analyses were performed using the Statistical Package for Social Sciences version 17.0 (SPSS Inc, Chicago, IL, USA). An assessment of normality was done initially. All numerical data are expressed either as the median (minimummaximum) or as the mean \pm standard deviation. All categorical variables are expressed as the number and percentage (n, \%). The Wilcoxon signed-rank test was used to compare the variables (visual acuity $[\log M A R]$ ). A $P$-value of $<0.05$ was considered to be statistically significant.

\section{Results}

Eighty-five eyes of 85 patients were enrolled. The mean age of the patients was $59.6 \pm 8.1(40-77)$ years. There were 45 females $(53 \%)$ and 40 males $(47 \%)$. The median follow-up time was 13 (6-48) months. All 85 patients had diabetes mellitus. Additionally, 48 patients had hypertension and 34 had cardiovascular disease. Laser endophotocoagulation was performed in all eyes. For tamponade, silicone oil was used in nine eyes $(10.5 \%), \mathrm{C}_{3} \mathrm{~F}_{8}$ gas was used in 25 eyes $(29.5 \%), \mathrm{SF}_{6}$ gas was used in 26 eyes $(30.7 \%)$, and air was injected in two eyes $(2.4 \%)$.

Preoperative BCVA was between 20/40 and 20/400 in six eyes $(7.1 \%)$, counting fingers in 20 eyes $(23.5 \%)$, and hand movements or light perception in 59 eyes (69.4\%). At 6 months postoperatively, BCVA was 20/200 or better in 58 eyes $(68.2 \%)$ and 20/40 or better in 17 eyes $(20 \%)$. Mean preoperative $\log$ MAR visual acuity changed from $2.62 \pm 0.6$ to $0.8 \pm 0.7$ postoperatively. This difference was statistically significant $(P=0.000$, Figure 1 , Table 1$)$. The BCVA increased in 79 eyes $(92.9 \%)$ postoperatively. No eyes showed a decrease in visual acuity. In six eyes, the visual acuity remained unchanged; however, visual acuity was hand movements in these eyes. Three of these six cases had atrophy of the optic nerve and two had plaque exudates in the macula. The last of the six eyes had optic atrophy 


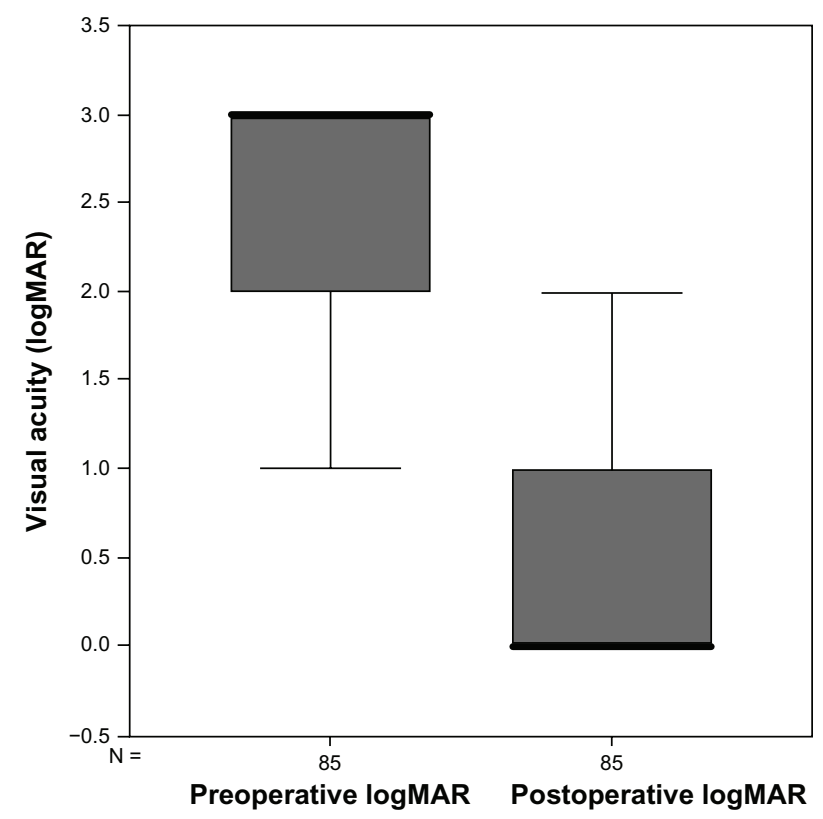

Figure I Box plot showing differences in visual acuity.

Abbreviations: logMAR, logarithm of the minimum angle of resolution; N, patient number.

secondary to neovascular glaucoma with visual acuity of hand movements.

Intraoperative complications were observed in six eyes. Iatrogenic retinal tears occurred in five $(5.8 \%)$ eyes, and one $(1.2 \%)$ eye had a posterior capsule tear (Table 2 ).

Details of the postoperative complications are given in Table 3. Postoperatively, a transient IOP rise $(>24 \mathrm{mmHg})$ was observed in 25 eyes (29.4\%). However, all were medically controlled with topical antiglaucomatous drugs. The next most common complication was moderate transient vitreous hemorrhage in 23 eyes (27.1\%). In 22 eyes, hemorrhage resolved in $12.8 \pm 3.9(7-21)$ days without any further surgery. Only one patient (1.2\%) developed retinal detachment that required reoperation. Neovascularization of the iris did not ameliorate in one eye (1.2\%), which had neovascular glaucoma preoperatively. Additional postoperative complications included transient corneal edema in five eyes (5.8\%), corneal epithelial defects in six eyes (7\%), and posterior synechia in four eyes $(4.7 \%)$, moderate anterior chamber reaction in four eyes $(4.7 \%)$, and hyphema in

Table I Distribution of BCVA (logMAR) before and after phacoemulsification combined with pars plana vitrectomy surgery

\begin{tabular}{lll}
\hline BCVA (logMAR) & Preoperative & Postoperative \\
\hline $0-1$ & $6(7.1 \%)$ & $75(88.2 \%)$ \\
2 & $20(23.5 \%)$ & $6(7.1 \%)$ \\
3 & $59(69.4 \%)$ & $4(4.7 \%)$ \\
\hline
\end{tabular}

Abbreviations: BCVA, best-corrected final visual acuity; logMAR, logarithm of the minimum angle of resolution.
Table 2 Intraoperative complications (percentage of total patients)

\begin{tabular}{ll}
\hline Intraoperative complications & Patients, n (\%) \\
\hline Corneal epithelial defects & $6(7)$ \\
Posterior capsule tears & $1(1.2)$ \\
latrogenic retinal tears & $5(5.8)$ \\
\hline
\end{tabular}

three eyes (3.5\%, Table 2). None of the patients developed fibrin transudation in the anterior chamber. Endophthalmitis occurred in no cases; no IOL-related complication like dislocation was observed either.

\section{Discussion}

Cataract is a frequent comorbidity in eyes with PDR. In addition to altering the patient's visual acuity, it is also a cause of visual disturbance to the surgeon during vitreoretinal surgery. Currently, it is still a controversy whether to leave the patient phakic during pars plana vitrectomy or to perform combined surgery. ${ }^{3}$ There has been some concern that simultaneous cataract surgery increases inflammation and also the risk of postoperative iris neovascularization, particularly in diabetic patients. ${ }^{11}$ In such cases, the aim is to maintain optimum visualization of the fundus with minor adverse effects and intraoperative/postoperative complications. Pars plana vitrectomy combined with cataract surgery is gaining popularity for cases in which cataract and vitreoretinal disorders exist coincidentally. On the other hand, due to the lack of vitreous support, cataract surgery is usually challenging in vitrectomized eyes, due to the increased risk of zonular dialysis and posterior capsular rupture. ${ }^{12}$

Cataract surgery prior to vitrectomy could also increase the risk of posterior segment complications due to the delay in intervention and surgical trauma. ${ }^{3}$ Thus, combining PPV with cataract surgery is reasonable. The combined procedure offers the advantages of a single procedure, including faster recovery time and cost-effectiveness. ${ }^{13,14}$ Moreover, this method allows thorough vitreous base surgery. ${ }^{3}$ Several studies reported PPV combined with phacoemulsification and IOL implantation as a safe and effective method.

Table 3 Postoperative complications (percentage of total patients)

\begin{tabular}{ll}
\hline Postoperative complications & Patients, n (\%) \\
\hline Corneal edema & $5(5.8)$ \\
Anterior chamber reaction & $4(4.7)$ \\
Hyphema & $3(3.5)$ \\
Posterior synechia & $4(4.7)$ \\
Transient intraocular pressure rise & $25(29.4)$ \\
Neovascular glaucoma & $\mathrm{I}(\mathrm{I} .2)$ \\
Vitreous hemorrhage & $23(27)$ \\
Retinal detachment & $\mathrm{I}(\mathrm{I} .2)$ \\
\hline
\end{tabular}


Postoperative visual outcome did not significantly differ between combined and sequential procedures. , $^{2,15-18} \mathrm{We}$ performed phacoemulsification and IOL implantation in all cases. Postoperatively, the visual acuity improved in 79 eyes (92.9\%) and did not change in only six eyes (7.1\%). The $\log$ MAR visual acuity improved significantly at postoperative month $6(P=0.000)$.

Although combined surgery offers the aforementioned advantages, it also has several drawbacks. Since the red reflex is poor, performing capsulorhexis could be challenging. Manipulations during posterior segment surgery could lead to corneal wound leak and anterior chamber loss, resulting in prolonged surgery. Miosis, hemorrhage from anterior segment structures, folds in Descemet's membrane, and corneal opacity due to edema following cataract extraction are the potential limitations of combined surgery. ${ }^{16}$ Lahey et al reported that the postoperative anterior chamber inflammation in combined surgery was more pronounced compared with single PPV. ${ }^{19}$ Also, several studies reported diffuse fibrin formation in the anterior chamber following combined cataract surgery and PPV. ${ }^{7,10,14,18,20}$ To suppress this inflammation, intracameral injection of triamcinolone acetonide was recommended. ${ }^{21}$ We injected triamcinolone acetonide intracamerally in all cases at the end of surgery, which we believe to prevent the formation of fibrin. In our series, only four eyes showed moderate inflammation in the anterior chamber which responded well to topical steroids. None of the patients showed severe inflammation.

In patients with diabetic vitreous hemorrhage, the rate of recurrent hemorrhage varies between $12 \%$ and $63 \% .^{20,22-26}$ In the present study, 23 eyes $(27.1 \%)$ developed mild hemorrhage whereas one had moderate hemorrhage requiring a second operation.

Neovascularization of the iris is a well known complication of PDR. ${ }^{7}$ In the present study, we had one patient who was diagnosed preoperatively as neovascular glaucoma, which did not resolve postoperatively.

Following combined surgery, a temporary rise in IOP may occur. A temporary IOP increase is reported to occur in $9.7 \%-25 \%$ of cases. ${ }^{17,18}$ We observed a temporary IOP rise in $29.5 \%$ of patients ( 25 eyes). The IOP returned to normal levels with antiglaucomatous medication. We consider that this transient increase in IOP could possibly be due to a retained ophthalmic viscosurgical device which was not thoroughly aspirated at the end of surgery.

The retrospective design may be a shortcoming of our study. However, given that our results are similar to those of previous studies involving combined and sequential procedures we propose that our results are reasonable. In conclusion, combined PPV and phacoemulsification had a safe and effective outcome. The potential limitations are minor. Considering the disadvantages of separate procedures and the advantages of the combined procedure, we believe that it could be safely performed on eligible patients.

\section{Disclosure}

The authors report no conflicts of interest in this work.

\section{References}

1. Bron AJ, Sparrow J, Brown NA, Harding JJ, Blakytny R. The lens in diabetes. Eye. 1993;7:260-275.

2. Blankenship GW, Machemer R. Long-term diabetic vitrectomy results. Report of 10 year follow-up. Ophthalmology. 1985;92:503-506.

3. Lee JY, Kim KH, Shin KH, Han DH, Lee DY, Nam DH. Comparison of intraoperative complications of phacoemulsification between sequential and combined procedures of pars plana vitrectomy and cataract surgery. Retina. 2012;32:2026-2033.

4. Thompson JT, Glaser BM, Sjaarda RN, Murphy RP. Progression of nuclear sclerosis and long-term visual results of vitrectomy with transforming growth factor beta-2 for macular holes. Am JOphthalmol. 1995;119:48-54.

5. Cheung CM, Hero M. Stabilization of anterior chamber depth during phacoemulsification cataract surgery in vitrectomized eyes. $J$ Cataract Refract. 2005;31:2055-2057.

6. Chang MA, Parides MK, Chang S, Braunstein RE. Outcome of phacoemulsification after pars plana vitrectomy. Ophthalmology. 2002;109: 948-954.

7. Honjo M, Ogura Y. Surgical results of pars plana vitrectomy combined with phacoemulsification and intraocular lens implantation for complications of proliferative diabetic retinopathy. Ophthalmic Surg Lasers. 1998;29:99-105.

8. Koenig SB, Han DP, Mieler WF, Abrams GW, Jaffe GJ, Burton TC. Combined phacoemülsification and pars plana vitrectomy. Arch Ophthalmol. 1990;108:362-364.

9. Jain V, Kar D, Natarajan S, et al. Phacoemulsification and pars plana vitrectomy: a combined procedure. Indian J Ophthalmol. 2007;55: 203-206.

10. Scharwey K, Pavlovic S, Jacobi KW. Combined clear corneal phacoemulsification, vitreoretinal surgery, and intraocular lens implantation. J Cataract Refract Surg. 1999;25:693-698.

11. Kadonosono K, Matsumoto S, Uchio E, Sugita M, Akura J, Ohno S. Iris neovascularization after vitrectomy combined with phacoemulsification and intraocular lens implantation for proliferative diabetic retinopathy. Ophthalmic Surg Lasers. 2001;32:19-24.

12. Wensheng L, Wu R, Wang X, Xu M, Sun G, Sun C. Clinical complications of combined phacoemulsification and vitrectomy for eyes with coexisting cataract and vitreoretinal diseases. Eur J Ophthalmol. 2009;19:37-45.

13. Lahey JM, Francis RR, Kearney JJ, Cheung M. Combining phacoemulsification and vitrectomy in patients with proliferative diabetic retinopathy. Curr Opin Ophthalmol. 2004;15:192-196.

14. Chung TY, Chung H, Lee JH. Combined surgery and sequential surgery comprising phacoemulsification, pars plana vitrectomy, and intraocular lens implantation: comparison of clinical outcomes. J Cataract Refract Surg. 2002;28:2001-2005.

15. Sisk RA, Murray TG. Combined phacoemulsification and sutureless 23 -gauge pars plana vitrectomy for complex vitreoretinal diseases. Br J Ophthalmol. 2010;94:1028-1032.

16. Sood V, Rahman R, Denniston AK. Phacoemulsification and foldable intraocular lens implantation combined with 23-gauge transconjunctival sutureless vitrectomy. J Cataract Refract Surg. 2009;35:1380-1384. 
17. Demetriades AM, Gottsch JD, Thomsen R, et al. Combined phacoemulsification, intraocular lens implantation, and vitrectomy for eyes with coexisting cataract and vitreoretinal pathology. Am J Ophthalmol. 2003;135:291-296.

18. Mochizuki Y, Kubota T, Hata Y, et al. Surgical results of combined pars plana vitrectomy, phacoemulsification, and intraocular lens implantation. Eur J Ophthalmol. 2006;16:279-286.

19. Lahey JM, Francis RR, Kearney JJ. Combining phacoemulsification with pars plana vitrectomy in patients with proliferative diabetic retinopathy: a series of 223 cases. Ophthalmology. 2003;110: 1335-1339.

20. Rivas-Aguiño P, Garcia-Amaris RA, Berrocal MH, Sánchez JG, Rivas A, Arévalo JF. Pars plana vitrectomy, phacoemulsification and intraocular lens implantation for the management of cataract and proliferative diabetic retinopathy: comparison versus two-step surgical approach. Arch Soc Esp Oftalmol. 2009;84:31-38.
21. Karalezli A, Borazan M, Akova YA. Intracameral triamcinolone acetonide to control postoperative inflammation following cataract surgery with phacoemulsification. Acta Ophthalmol. 2008;86:183-187.

22. Yang CM. Surgical treatment for diabetic retinopathy: 5-year experience. J Formos Med Assoc. 1998;97:477-484.

23. Schachat AP, Oyakawa RT, Michels RG, Rice TA. Complications of vitreous surgery for diabetic retinopathy. II. Postoperative complications. Ophthalmology. 1983;90:522-530.

24. Novak MA, Rice TA, Michels RG, Auer C. Vitreous hemorrhage after vitrectomy for diabetic retinopathy. Ophthalmology. 1984;91: 1485-1489.

25. West JF, Gregor ZJ. Fibrovascular ingrowth and recurrent hemorrhage following diabetic vitrectomy. Br J Ophthalmol. 2000;84:822-825.

26. Cooper B, Shah GK, Grand MG, Bakal J, Sharma S. Visual outcomes and complications after multiple vitrectomies for diabetic vitreous hemorrhage. Retina. 2004;24:19-22.
Clinical Ophthalmology

\section{Publish your work in this journal}

Clinical Ophthalmology is an international, peer-reviewed journal covering all subspecialties within ophthalmology. Key topics include: Optometry; Visual science; Pharmacology and drug therapy in eye diseases; Basic Sciences; Primary and Secondary eye care; Patien Safety and Quality of Care Improvements. This journal is indexed on

Submit your manuscript here: http://www.dovepress.com/clinical-ophthalmology-journal

\section{Dovepress}

PubMed Central and CAS, and is the official journal of The Society of Clinical Ophthalmology (SCO). The manuscript management system is completely online and includes a very quick and fair peer-review system, which is all easy to use. Visit http://www.dovepress.com/ testimonials.php to read real quotes from published authors. 